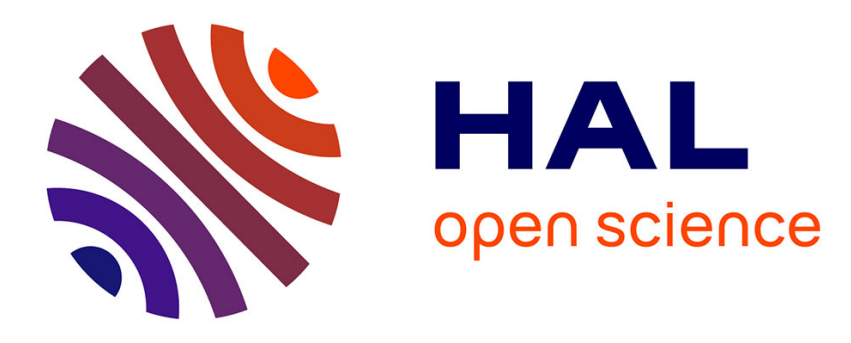

\title{
Investigation of polymer deformation by positron annihilation
}

S. Wang, Chen Wang, Biao Wang

\section{To cite this version:}

S. Wang, Chen Wang, Biao Wang. Investigation of polymer deformation by positron annihilation. Journal de Physique IV Proceedings, 1993, 03 (C4), pp.C4-275-C4-278. 10.1051/jp4:1993443 . jpa00251486

\section{HAL Id: jpa-00251486 https://hal.science/jpa-00251486}

Submitted on 1 Jan 1993

HAL is a multi-disciplinary open access archive for the deposit and dissemination of scientific research documents, whether they are published or not. The documents may come from teaching and research institutions in France or abroad, or from public or private research centers.
L'archive ouverte pluridisciplinaire HAL, est destinée au dépôt et à la diffusion de documents scientifiques de niveau recherche, publiés ou non, émanant des établissements d'enseignement et de recherche français ou étrangers, des laboratoires publics ou privés. 


\title{
Investigation of polymer deformation by positron annihilation
}

\author{
S.J. WANG, C.L. WANG and B. WANG \\ Department of Physics, Wuhan University, Wuhan 430072, China
}

\section{ABSTRACT}

Positron lifetimes in polytetrafluroethylene (PTFE) and polyethylene (PE) have been measured as a function of residual deformation e. For PTFE, the variation of o-Ps intensity shows a three-stage processes: the elastic region $(a=0-20 \%)$, plastic-flow region $(e=20-80 \%)$ and strain-strengthening region $(\varepsilon=80-180 \%)$. The changes of free-volume hole size and concentration suggest the separation, scission and orientation of segments. For PE, the o-Ps parameters are sensitive to the elastic and plastic regions. Particularly, the hole concentration decreases linearly with $e$, which indicates the crystallization during deformation.

\section{INIRODUCTION}

The correlation between microstructure and macroscopic properties of polymers has been of interest for many years [1]. It was found that the tensile strengths and Young's moduli of polymers are rather lower than the expected values, and different mechanisms have been proposed on the deformation of seni-crystalline polymers [2]. In order to discern the different physical processes during deformation, we performed the positron lifetime experiment on the glassy PTFE and rubbery PE at room temperature as a function of $\mathbf{e}$.

\section{EXPERTMENT}

The dumbbell-shape specimens were cut from two pieces of PTFE and PE plates. A mechanical stretching device provides a stretch rate of $4 \% \mathrm{~min}^{-1}$ and fixed the elongated specimens. When the reaches a preset value (i.e., 10\%, 20\%, etc), the stretch was stopped. Immediately a $15_{\mu} \mathrm{Ci}$ 镝 positron source sealed on $\mathrm{Ni}$ foil $\left(1.7 \mathrm{mg} \mathrm{cm}^{-2}\right.$ ) was placed between the two specimens. Positron lifetime measurements in situ were performed using a fast-fast coincident system which has a time resolution of 250ps. A million counts were collected for each spectrum within about 1 hour. 


\section{RESULTS AND DISCUSSION}

\section{(1). Microstructural changes in PTFE}

Positron spectrum of PTFE has been best resolved into four components by using PATFIT program $[3,4\}$. We observed that the longest component $\tau_{4}$ is particularly sensitive to , where $\tau_{4}$ is from o-Ps annihilation in the free-volume holes of amorphous regions [6], and its intensity is proportional to the hole concentration.

There is a good correlation between the o-Pg intensity $I_{4}$ and the true stress of PTFE. We have measured the true stress-deformation curves of PTFE (the stretch rate is $150 \%$ per min.), which clearly shows three deformation stages and $=10 \%$ is the yield point [7]. In Fig. 1 the variation of $I_{1}$ indicates the three stages of PTFE deformation, i.e., the elastic $(e=0-20 \%)$, plastic-flow $(e=20-80 \%)$ and the strainstrengthening region $(e=80-180 \%)$. The yield point indicated by $I_{4}$, i.e. $e=20 \%$, is somewhat retarded in comparison with that indicated by stress-deformation curve. This fact can be interpreted by relaxation effects. Mechanical experiments [10] have shown that the decrease of stretch rate can retard the yield point. For PAS measurement the stretch rate is $4 \%$ per minute, which is maller than $150 \%$ per minute for o-e measurement; and when $e$ reaches a preset value the stretch was stopped for 1 hour in order to acquire data. So the PTFE chains have enough time to rearrange themselves and chain slip is retarded.

As shown in Fig.1 and 2, in the elastic region $(e=0-20 \%)$, we observed the hole concentration is nearly constant, while its size has a slight increase with $e$. It indicates a small separation of segment without the hole creation. At the end of elastic stage $(e=20 \%)$, the larger stresses can induce the separation of segments and the creation of holes and lead to the increases of $I_{4}$ and $\tau_{4}$.

In the plastic-flow stage $(e=20-80 \%)$, the microstructure undergoes dramatic changes. Due to inter-molecular friction force [10], the stress can be transferred from one chain to another and results in the slip, separation and orientation of chains. The constant $I_{i}$ suggests that no new holes are expected to be created, and the separation of segments only induces the enlargement of holes in the period of $e=20 \%-60 \%$. When $e^{=60-80 \%}$, the dramatic decrease in o-Ps lifetime $\tau_{4}$ is due to the orientation of segments. In polymers the free-volume hole is an unoccupied space, around which the segments are arranged disorderly. Under a larger stress, the segments tend to align and have more order arrangenent $[7,10]$, which would effectively reduce the hole size in the region of $e=60-80 \%$.

At the end of plastic-flow stage $(e=80 \%)$, a step increase in $I_{4}$ is observed, probably resulting from the scission of chains and the creation of more freeradicals and chain ends. Since PAS experiment is performed at $T<T_{g}\left(T_{g}=388 \mathrm{~K}\right.$ for PTFE), the PTFE is in glassy state and the scission of chains is possible due to the anchorage of entanglements and crystallites. Based on the step increase in $I_{4}$ at $e=80 \%$, the scission of chains takes place and more chain ends and free radicals are produced, so a larger number of new free-volume holes are created. In the strain-strengthening stage, both $I_{4}$ and $\tau_{4}$ have no obvious changes. The possible reasons are: 1 ). There is a dynanic balance between production and diminution of free-volume holes due to the active motion of chain ends and free-radicals $[9]$; 2). The orientation degree of segments reaches a saturation level. When $>160 \%, I_{4}$ 
begins to increase again until PIFE is broken at $e=185 \%$.

\section{(2). Microstructural changes in $\mathrm{PE}$}

The measurement of stress vs $e$ shows a three-stage processes, namely, the elastic $(e=0-20 \%)$, strain-softening $(e=20-40 \%)$ and plastic-flow $(e=40-190 \%)$. Lifetime spectrum of $\mathrm{PE}$ is resolved into three components, in which the longest-lived $\tau_{3}$ is from o-Ps annihilation in free-volume holes in amorphous regions, and the intermediate $\tau_{2}$ is from positron annihilation in the defects of crystalline regions. In the elastic region, the increases of size and concentration of free-volume holes in the amorphous region may result from the scission of chains [9] and the increase of crystalline-amorphous interfaces. Near the yield point $(e=20 \%)$, the maximum in hole size and concentration provides an experimental evidence for the free-volume theory on deformation [8]. The increases in $I_{2}$ and $\tau_{2}$ shown in Fig.3-4 coincide with the structural changes from the spherulites to the microfibril and the generation of grain boundaries [1]. While the maximum $\tau_{2}$ at $t=20 \%$ indicates the coalescence of defects under high stress. In the strain-sof tening stage, the nearly constant $I_{3}$ and If imply that the microstructural changes take place mainly in the crystaline regions [9]. In the plastic-flow stage, the decrease of $I_{3}$ arises from the stressinduced crystallization, while the nearly constant $\tau_{3}$ may be related to the constant stress vs $e$. In this stage, $\tau_{i}$ reveals a continuous decrease but $I_{\eta}$ increases with $e$, which shows the rearrangement of chains in the crystalline regions.

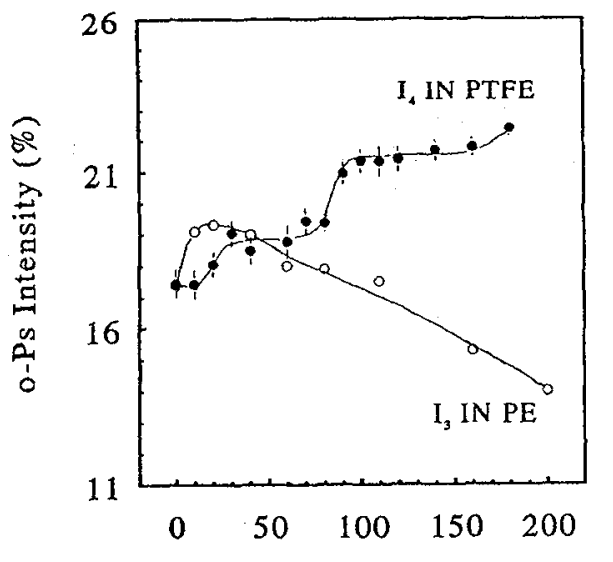

Deformation $\varepsilon(\%)$

Fig. 1 The plot of o-Pg intensity vs.e

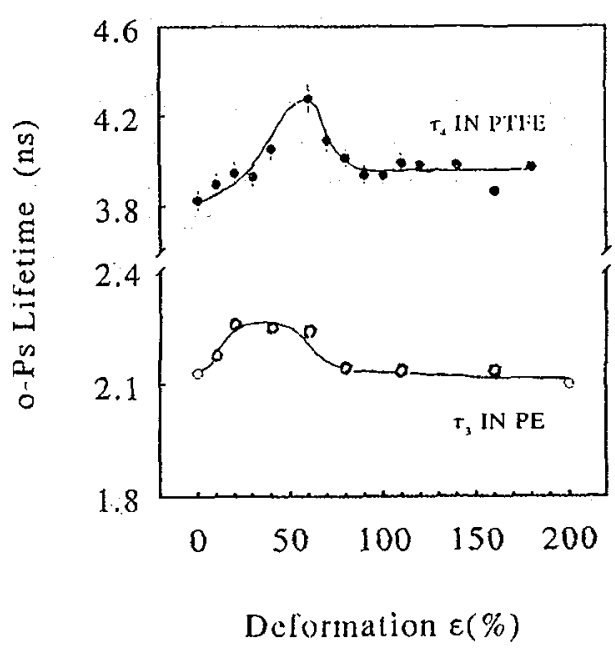

Fig.2 The plot of o-Ps lifetime vs.e 


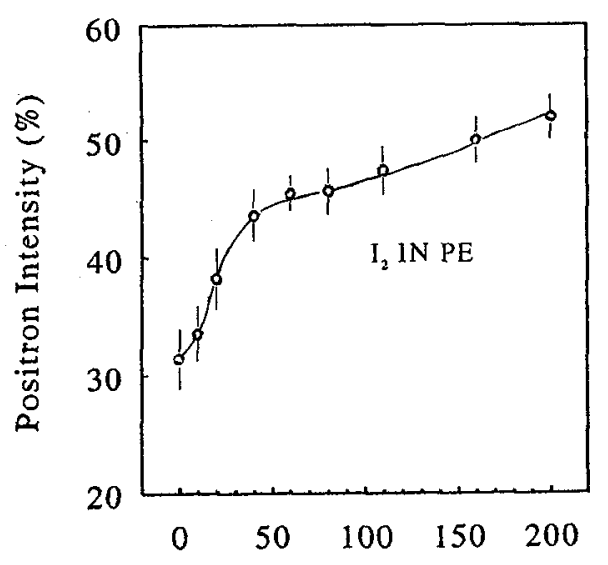

Deformation $\varepsilon(\%)$

Fig. 3 The plot of positron intensity $I_{2}$ vs.e for $\mathrm{PE}$

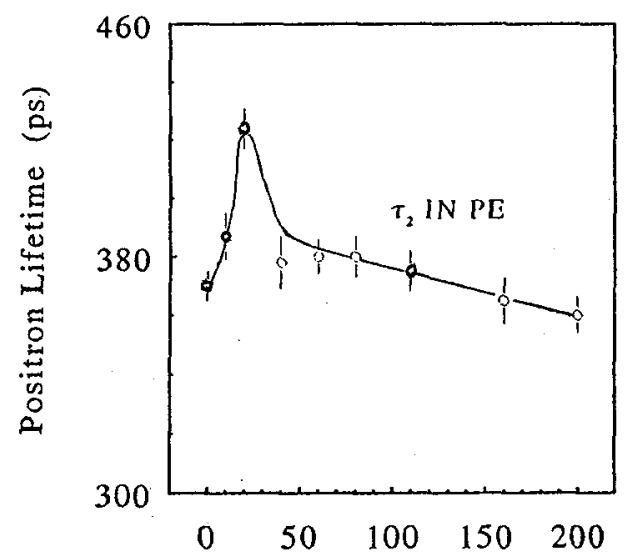

Deformation $\varepsilon(\%)$

Fig. 4 The plot of positron lifetime I? vs.e for $\mathrm{PE}$

\section{REFGRPANCKS}

[1] Samuels, R.J, Structured Polymer Properties (Wiley, New York, 1974)

[2] Kobayashi, K, in Polymer Single Crystal, ed. Geil, P.H (Wiley, New York, 1963) p473; Juska, T and Harrison, I.R, Polym.Eng.Rev. 2(1982) 13; Peterlin, A, Colloid Polym.Sci. 256(1987) 357

[3] Kirkegaard, P, et al. Comp.Phys.Commun. 23(1981) 307

[4] Kindl, P and Sormann, H, Phys.Stat.Sol.(a) 66(1981) 627

[5] Lin, D and Wang, S.J, J.Phys.C 4(1992) 3331

[6] Jean, Y.C, Microchem.J. 42(1990) 972

[7] Wang, C.L, Wang, B, Li, S.Q. and Wang S.J., J.Phys.C (to be published)

[8] Ward, I.M, Mechanical Properties of Solid Polymers (Interscience, London, 1983)

[9] Kausch, H.H, Polymer Fracture (Springer-Verlag, Berlin, 1978)

[10] Hearle, J, Polymers and Their Properties Vo.1 (Ellis Horwood, Chichester, 1982) 